\title{
Numerical Simulation and Analysis of Bearing Capacity of U Beam Steel Arch
}

\author{
Zhang Zhongke \\ State Key Laboratory of Gansu Advanced Non-ferrous Metal \\ Materials \\ Lanzhou University of Technology, \\ Lanzhou, Gansu, China \\ zhangzke@lut.cn

$$
\text { Lu Qin }
$$ \\ State Key Laboratory of Gansu Advanced Non-ferrous Metal \\ Materials \\ Lanzhou University of Technology, \\ Lanzhou, Gansu, China
}

\begin{abstract}
U beam steel arch has widely been used in nonferrous metal mines support especially in deep mining due to its ductile and high bearing capacity. This paper aimed at the simulation analyses based on the finite element method for $U$ beam steel arch production. The comparison of the bearing capacity between the roll bending and die forming were studied. The law was also been analyzed as the forming radius. The results showed that the maximum effective strength of the die forming is the twice of the roll bending. The position of the maximum effective stress of the die forming is at the molded corner, and it appears at the root of the arch of the roll bending. The effective strength increases as the arch radius.
\end{abstract}

Keywords- U beam steel arch, Roll bending, Bearing capacity, Numerical simulation

\section{INTRODUCTION}

Steel arches, being very ductile, have been used extensively as ground supports in weak rock strata. They are usually fabricated by cold-bending of segments of steel U-section about the flange axis and attaching them by fish plates ${ }^{[1]}$. Beams generally carry vertical gravitational forces but can also be used to carry horizontal loads (i.e., loads due to an earthquake or wind). The loads carried by a beam are transferred to columns, walls, or girders, which then transfer the force to adjacent structural compression members. In light frame construction the joists rest on the beam. The U-steel arched support is shown as Fig. 1.

To evaluate the performance of a support system, the engineer must therefore capture the deformation within the rock mass. The analysis of a support-reinforcement system is complicated if the support is to be simulated beyond the point of failure of some of the elements as the problem becomes

\author{
Wang Xijing \\ State Key Laboratory of Gansu Advanced Non-ferrous Metal \\ Materials \\ Lanzhou University of Technology, \\ Lanzhou, Gansu, China \\ wangxj@lut.cn \\ Zhu Zhenzer \\ State Key Laboratory of Gansu Advanced Non-ferrous Metal \\ Materials \\ Lanzhou University of Technology, \\ Lanzhou, Gansu, China
}

significantly non-linear; the failure of one part of the system could lead to failure of another and another and so on. ${ }^{[2]}$

Currently u-steel arch are mainly been produced by die forming and roll bending machine forming ${ }^{[3]}$. In order to comparison the characteristics of the two ways, this paper studied the stress analysis and the bearing performance by numerical simulation method of different $U$ beam steel arch.

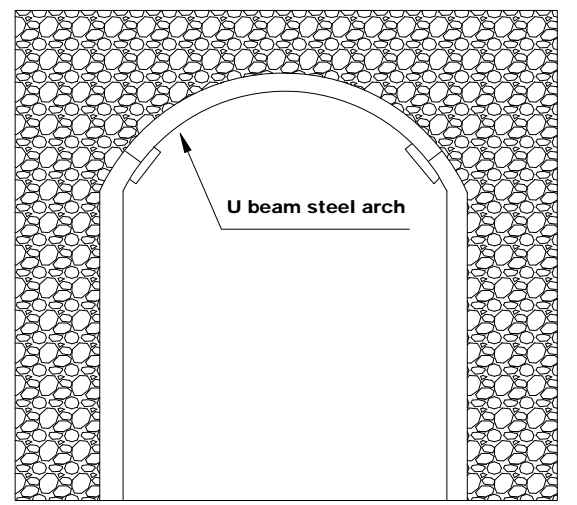

Figure 1. The diagram of $U$ beam steel arched support

\section{FINITE ELEMENT MODELING}

\section{A. Geometrical set up}

The investigation was carried out on $25 \mathrm{U}$ beam steel specimens. Considering the roll bending process characteristics the improved FE-model was developed in the FE-software Ansys11.0/workbench. The model of the tool's geometry was set up by Pro/E CAD software. Simulation investigations were conducted for $U$ beam hot rolled steel made of carbon steel $16 \mathrm{Mn}$ with an height of $110 \mathrm{~mm}$, a wall thickness of $17 \mathrm{~mm}$, radius $1.0 \mathrm{~m}, 1.5 \mathrm{~m}, 2 \mathrm{~m}$ and $2.5 \mathrm{~m}^{[4]}$. 


\section{B. Material properties}

The article researched the elasto-plastic material of $16 \mathrm{Mnl} \#$ steel, Figure 1 shows the U beam steel material parameter. The the elasto-plastic material model for the FEM modeling is assumed as bilinear represented by the red line with a young's modulus of $212 \mathrm{GPa}$, a yield stress of $450 \mathrm{MPa}$ and The Poisson's ratio is assumed 0.310 and the density of the material of the plate is $7870 \mathrm{~kg} / \mathrm{m}^{3}$.

TABLE I. MECHANICAL PROPERTIES

\begin{tabular}{|l|c|c|c|c|}
\hline \multirow{4}{*}{ Material } & \multicolumn{4}{|c|}{ Mechanical properties } \\
\cline { 2 - 5 } & $\begin{array}{c}\text { Elastic } \\
\text { modulus } \\
(\mathbf{G P a})\end{array}$ & $\begin{array}{c}\text { Poisso } \\
\text { n's } \\
\text { ratio }\end{array}$ & $\begin{array}{c}\text { Density } \\
(\mathbf{k g} / \mathbf{m} 3)\end{array}$ & $\begin{array}{c}\text { Yield } \\
\text { stress } \\
(\mathbf{M P a})\end{array}$ \\
\hline $16 \mathrm{Mn}$ & 212 & 0.310 & 7870 & 450 \\
\hline
\end{tabular}

\section{Meshing techniques}

The geometry of $U$ beams steel workpiece in a typical roll bending and die forming are modeled and analyzed. The geometry of the modeled part and the mesh density are shown in Fig. 2.

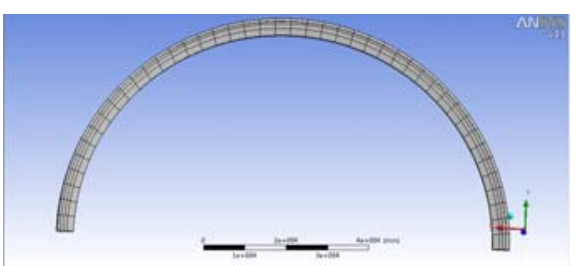

a) The $U$ beam steel arch of rolling-bending

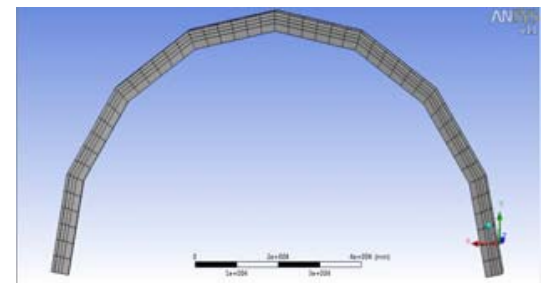

b) The $U$ beam steel arch of die forming

Figure 2. The mesh model of $U$ beam steel arch

\section{Boundary Conditions}

The arch of $U$ beam steel is subjected to the straight down axial compression. Hence, while modeling, the bottom legs of the $U$ beam steel are fixed and the top of $U$ beam steel is subjected to compression by the application of 300MPa under uniformly distributed load pressure.

\section{RESULTS AND DISCUSSIONS}

\section{A. Deformation comparison of forming process}

Figure 3 shows the deformation distributions of the $2 \mathrm{~m}$ radius $U$ beam steel arch of the various forming process. Figure 3.a shows the arch's total deformation of rolling- bending process and Figure 3.b is the arch's total deformation of die forming process. Due to the load pressure, large deformations are caused and big stress concentrated in the $\mathrm{U}$ beam steel. When a force is applied at the negative Y direction, a maximum displacement occurs at the central node of the arch of U beam steel.

In the deformation of $U$ beam steel of the roll bending process the high stresses are found. The maximum deformation in the 300MPa uniformly distributed load pressure contacting with the U beam steel is $0.017899 \mathrm{~mm}$, the smallest amount of deformation is a $0.0019888 \mathrm{~mm}$. Although the area of the maximum deformation the roll bending process is bigger than that of die forming, the size of deformation is smaller. From the Figure 3, it can also been seen that the deformation distribution of entire arched is centerline and symmetry.

Figure 3.b is the deformation of die forming u-beam arch. The maximum deformation capacity is $0.43035 \mathrm{~mm}$, far greater than the maximum amount of deformation of rolling-bending steel arch. The maximum deformation region is also located in the vault, the minimum deformation is $0.047817 \mathrm{~mm}$. The entire arch is far greater than the minimum deformation rollformed steel structure under the host in a dangerous position.



a) The arch's total deformation of rolling-bending process

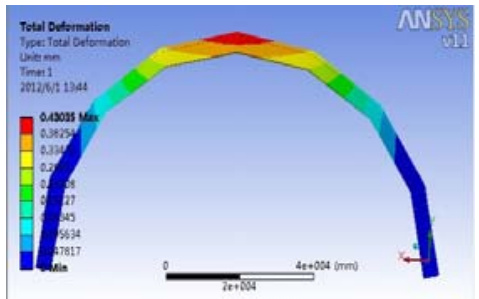

b) The arch's total deformation of die forming process

Figure 3. the deformation of the arch of $U$ beam steel

\section{B. Effect of forming process on bearing capacity}

For the bearing capacity of the $U$ beam steel, the effective strain and stress of various processes at the same load were studied. The result of the effective stress and strain distribution of $2 \mathrm{~m}$ radius $\mathrm{U}$ beam steel arched support obtained from the finite-element analysis are shown in Figure 4. The bearing capacity deviate from each other, because the shape after deform are different. The stresses in the chord members except for the bend areas are moderate, the distribution is similar to that expected from axial force and bending.

In accordance with the results of the simulation, the highest stresses of rolling-bending process can be found in the arch feet. The maximum effective stress can reach $47932 \mathrm{MPa}$, the 
minimum effective stress 617.1MPa (as shown fig 4.a). In comparison, the highest stresses of compression molding

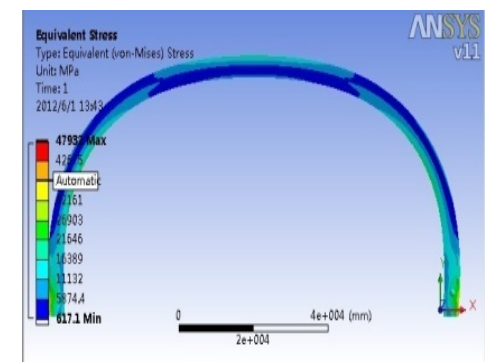

a)The effective stress distribution of rolling-bending process



b) The effective stress distribution of die forming process



c)The effective strain distribution of rolling-bending process

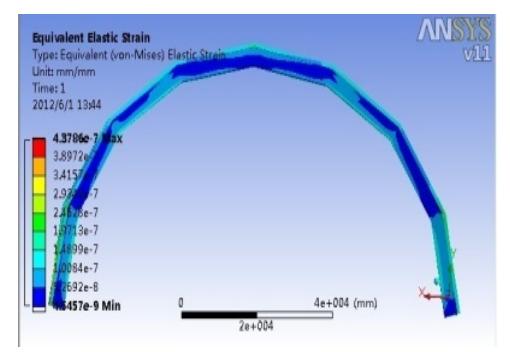

d) The effective strain distribution of die forming process

Figure 4. The effective stress and strain distribution in the $U$ beam steel at $10 \mathrm{kN} /$ jack load level of various processes.

Process can be found at the arch folded corner. The maximum effective stress can reach $92827 \mathrm{MPa}$, the minimum effective stress 343.68MPa (as shown fig 4.b). This implies that when the force was loaded on the main girder with the uniformly distributed load, the maximum effective stress of die forming arch was two times of that of the rolling-bending arch.
The stresses in the die forming arch except for the folded areas are moderate, the distribution is similar at the bend segment. The bearing capacity deviate from each other, because the shape after deform are different.

The maximum equivalent elastic strain of rolling-bending arch is $2.261 \mathrm{e}-7 \mathrm{~mm} / \mathrm{mm}$; the minimum effective elastic strain is $2.9019 \mathrm{e}-9 \mathrm{~mm} / \mathrm{mm}$ (as shown fig 4.c). In comparison, the highest stresses of die forming process can be found at the arch folded corner. The maximum effective strain can reach $4.3786 \mathrm{e}-7 \mathrm{~mm} / \mathrm{mm}$; the minimum effective strain is $4.5457 \mathrm{e}-9$ $\mathrm{mm} / \mathrm{mm}$ (as shown fig 4.d).

For $2 \mathrm{~m}$ radius $\mathrm{U}$ beam steel, the equivalent elastic strain and equivalent stress are all smaller than die forming arch, stress concentrated is small; the deformation of the two type arch is different. The deformation distribution of roll-bending arch is symmetric of the center line, but the deformation of die forming arch is segment distribution. The maximum deformation of roll bending type u steel arch appears at the top of arch, and the maximum deformation appears at folding location. Roll bending steel maximum stress strain regional appears in arch feet location; Maximum stress-strain region of die forming type u steel arch frame occurred mainly in the arch folded corner location, and u-shaped steel arches with folding legs on both sides, and each equivalent elastic transition between the folding significantly, stress concentration is large, prone to inner corner notched, brittle fracture failure occurs. So the roll-bending arch has better security than die forming arch and mechanical properties of homogeneity, with better reliability in structure.

\section{Effect of radius on bearing capacity}

There is $1.5 \mathrm{~m} \sim 2.5 \mathrm{~m}$ radius U-steel arch usually used as mine supports. The bearing capacity of various radiuses is different. The effect of radius on bearing capacity is also studied. In this paper the radius selected to analysis is $1 \mathrm{~m}, 1.5$ $\mathrm{m}, 2 \mathrm{~m}$ and $2.5 \mathrm{~m}$.

From the figure 5, the maximum effective stress of radius 1 $\mathrm{m}$ can reach $16336 \mathrm{MPa}$, and it is $28199 \mathrm{MPa}$ when the radius is $1.5 \mathrm{~m}$. It can be seen that the roll-bending U-steel arches of radius $1 \mathrm{~m}$ and $1.5 \mathrm{~m}$ (fig5.a, fig5.c) have smaller elastic stress and stress concentration than that of $2 \mathrm{~m}$ steel arches (fig fig4.a). Small radius of U-steel arches has a distinct advantage at stress and strain.

It can also be seen the same law that the die forming Usteel arches of radius $1 \mathrm{~m}$ and $1.5 \mathrm{~m}$ (fig5.b, fig5.d) have smaller elastic stress and stress concentration than that of $2 \mathrm{~m}$ steel arches (fig4.b). Small radius of U-steel arches has a distinct advantage at stress and strain. So the small radius arches is the higher safety structure than the big radius arches because of the small stress-strain.

For the radius of 2.5 meters of $\mathrm{u}$ beam steel arches, the effect of strain, stress concentration of roll type is smaller than molded steel. The structure of rolling-bending arch has more good bearing, high reliability than die forming arch. 


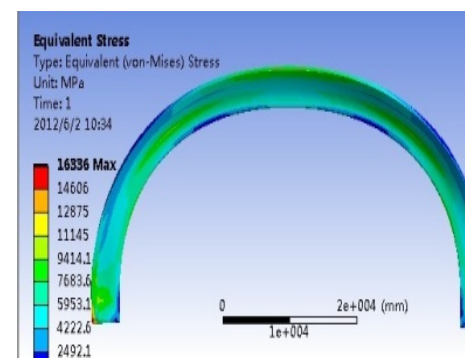

(a)

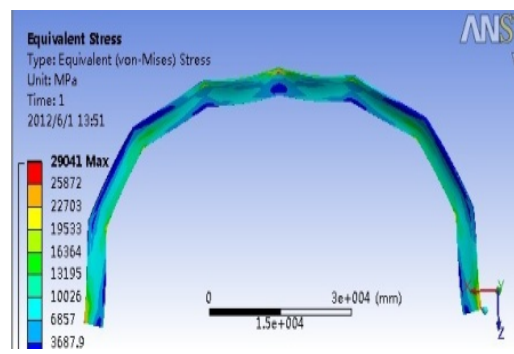

(d)



(b)

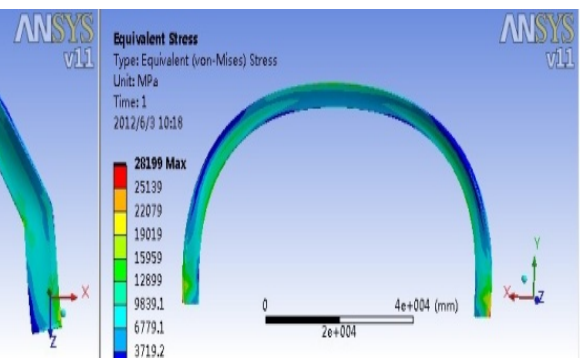

(c)



(e)

Figure 5. The radius effect on the stress and the strain distribution: (a) The 1m radius effective stress distribution of rolling-bending process, (b) The 1m radius effective strain distribution of die forming process, (c) The $1.5 \mathrm{~m}$ radius effective stress distribution of rolling-bending process, (d) The $1.5 \mathrm{~m}$ radius effective stress distribution of die forming process , (e) The $2.5 \mathrm{~m}$ radius effective stress distribution of rolling-bending process, (f) The $2.5 \mathrm{~m}$ radius effective stress distribution of die forming process

Compared to various radiuses of $u$ beams steel arches, the arch equivalent radius of 2.5 meters, the strain is more than a radius of $1 \mathrm{~m}, 1.5 \mathrm{~m}$ and $2 \mathrm{~m}$ arch. That is, the larger the radius, structural more reliability, and prone to more stress concentration risk of larger stress and strain.

\section{CONCLUSIONS}

(1) Compare to die forming arch, the rolling-bending arch has smaller equivalent elastic strain small, stress, stress concentrated. The maximum deformation of rolling-bending arch is the top of arch and die forming arch is at fold corner (feet on both sides of u steel arch). The equivalent stress of roll bending steel is twice of die forming arch.

(2) The equivalent stress of die forming and rollingbending arch all become larger as the radius increase. So the arches with small radius have more security than that of large radius.
(3) rolling-bending arch has better security than the die forming arch as the uniformity mechanical properties, and the structure better reliability.

\section{REFERENCES}

[1] H.S. Mitri, U.H. Khan, "Design guidelines for steel arch supports in underground mining, " Mining Science and Technology. Canada, Volume 13, Issue 1, pp. 37-44, July 1991.

[2] Beck, D., Kassbohm, S. and Putzar, G., "Multi-scale simulation of ground support designs for extreme tunnel closure”. In Proceedings of Caving2010: Second Int. Symposium on Block and Sublevel Caving . Perth, Western Australia. pp. 20-22 ,April 2010.

[3] Vollertsen F, Sprenger A, Kraus J and Arnet H. "Extrusion, channel, and profile bending: a review, "Journal of Materials Processing Technology. Netherlands . Volume 87, pp. 1-27, March 1999.

[4] Li Bing, He Zhengjia, Chen Xuefeng.“ANSYS Workbench simulation and optimization design,” Tsinghua University Press, China. pp. 28-46, August 2008. 